\title{
As carreiras jurídicas no Estado de S. Paulo*.
}

\author{
A. Almeida Júnior \\ Catedrático de Medicina Legal da Faculdade \\ de Direito da Universidade de São Paulo
}

"Troppi Avvocati!" - é o título do pequeno livro de Piero Calamandrei, publicado em 1920, no qual o conhecido processualista da Universidade de Florença, depois de afirmar a pletora de advogados na Itália de antes da primeira guerra, aponta os males resultantes daquele fenômeno. Os advogados de então, na Península, distribuíam-se, segundo Calamandrei, em dois grupos; uma escassa minoria formada pelos "que trabalham muito e ganham muito", e uma imensa maioria constituída pelos que, "não havendo logrado emergir da mediocridade", labutam desesperadamente "para matar a fome" E o autor adverte: "A existência dêsse proletariado forense, que piora de ano em ano graças ao aumento de seu efetivo, como um rio em enchente e cujas águas tanto mais se turvam quanto mais se avolumam, é a causa infeliz de todos os males da profissão". No elenco de tais males (diz êle) sobressaem "a deterioração moral da advocacia" e a sua "decadência intelectual", pois a pletora, se de um lado "estimula a litigiosidade e a má fé judicial", de outro constitui impulso para substituir o manuseio dos livros pela prática da chicana.

A que nível teria subido por aquêle tempo, na Itália, a pletora denunciada por Calamandrei? Êle mesmo o res-

* Boletim n.o 2 do Grupo de Trabalho instituído pelo Governador Carvalho Pinto para o fim de estudar as condições do ensino superior paulista, e cujo presidente é o autor do relatório acima. 
ponde, apoiado em dados comparativos, que menciona. Eis o índice de então, ou seja o número de advogados por cem mil habitantes de quatro países de organizações judiciárias muito próximas entre si: Austria, 18; Alemanha, 18; França, 26; Itália, 59. "A primasia dos italianos (conclui o autor) é aqui, infelizmente, manifesta".

\section{Novos tempos, novos padrões.}

De lá para cá transcorreu quase meio século e, nesse interregno, duas trágicas conflagrações produziram na vida civilisada mudanças extensas e profundas, de caráter político, social e econômico. Devemos procurar, portanto, para padrões de referência, estatísticas mais recentes. Essas estatísticas, fomos encontrá-las em dois países altamente representativos como amostras daquelas mudanças: a França e os Estados Unidos, cujos dados nos foram obtidos, respectivamente, pelo ministro Paulo Carneiro, nosso delegado junto à Unesco, e pelo Consulado Geral norte-americano de São Paulo.

Na França o número de advogados (inclusive os estagiários), e os respectivos indices por cem mil habitantes, têm sido ùltimamente os seguintes:

$$
\begin{aligned}
& 1945-6.472 \text { advog. ou } 16,3 \text { p. } 100 \text { mil hab. } \\
& 1950-7.440--18,0--<- \\
& 1956-6.785--15,7---- \\
& 1958-6.933--15,6----
\end{aligned}
$$

E o "Bureau" Universitário Estatístico de Paris, ao fornecer os dados acima, acrescenta êste reparo: "A Associação Nacional supõe que os efetivos permanecerão estacionários no decurso dos próximos anos, a não ser que as associações de advogados e sobretudo o desenvolvimento de especializações criem novas necessidades."

Mas vamos aos Estados Unidos, onde os efeitos do desenvolvimento e das especializações já se fizeram sentir 
com intensidade. Alí, a proporção de advogados, bastante elevada desde o século XIX (elevada segundo os padrões europeus), tem crescido quase sem interrupção. Eis os seus efetivos e respectivos índices em três anos distintos:

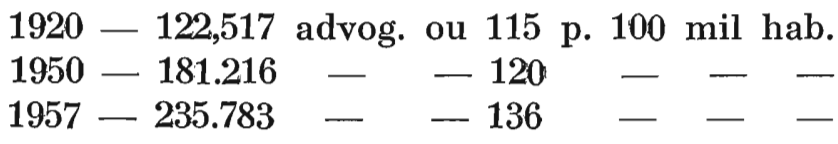

Importa observar, entretanto, que os dados acima, referentes aos Estados Unidos, englobam todos os juristas, inclusive os inativos e também, em duplicata, os que, dentro da carreira, exercem dois encargos distintos. Feitas as deduções correspondentes a essas parcelas, o total de 1957 desce para 223.662 juristas, com a seguinte distribuição percentual, em números redondos:

Advocacia liberal .

$77 \%$

Advocacia de partido

$9 \%$

Poder judiciário .

$4 \%$

Servidores públicos

$10 \%$

Isto nos leva a concluir que em 1957 havia nos Estados Unidos cêrca de 192.500 advogados, dos quais 175.200 , aproximadamente, exerciam a advocacia liberal (a grande maioria em escritórios individuais, os demais reunidos em sociedade). Os restantes 17.400 trabalhavam por conta exclusiva de emprêsas industriais, de instituições educacionais ou de outras entidades privadas. Sabendo-se que a população norte-americana, em 1957, fôra calculada em 171.229.000 habitantes, infere-se que o índice de advogados daquele país, no referido ano, foi, em números redondos, de 112 por cem mil habitantes. E, em contraste com a França, que em 1958 se julgava satisfeita com um indice sete vêzes menor, os Éstados Unidos entendem, segundo alguns, que, "em virtude da progressiva complexidade da ordem econômica e social", a demanda de serviços advocatícios tende a elevar-se ("Education for the Professions" _- "Office of Education", Washington, 1955). Um dos fa- 
tôres dessa tendência, é a diversidade do direito substantivo entre os quarenta e oito Estados federados, fato que obriga o advogado a especializar-se ou a trabalhar integrando-se numa equipe. Por êsse e por outros motivos, "parece duvidoso que se possa afirmar que nos Estados Unidos há excesso de advogados" - escreveu Harold LASKI. Mas acrescentou, com base em inquérito de 1938, que êsses profissionais, ali, ganham pouco. ("The American Democracy", 1949, pág. 574). Nossos informes sôbre o assunto, mais recentes que os de LASKI, contam que em 1950 a situação era a seguinte: $3,5 \%$ dos advogados classificavam-se como vivendo em penúria, pois ganhavam por ano menos de 1.000 dólares; $5,4 \%$ tinham rendimento considerado "estrito", entre mil e dois mil dólares anuais; e assim por diante, até os $28,1 \%$ que, percebendo mais de dez mil dólares por ano, eram postos na categoria dos "abastados". A renda mediana dos advogados, no referido ano, foi de 6.257 dólares, superada, na classe dos profissionais liberais, sòmente pela renda dos médicos, que atingiu a 8.115 dólares. Tais informes constam do volumoso trabalho do Prof. Donald Bogue, "The Population of the United States", 1959, pág. 545. Mas, sôbre a fidedignidade das declarações de renda, pode haver sempre dúvidas.

Em resumo, para sopesar melhor a situação paulista (só paulista, porque no tocante ao Brasil em geral nossos dados são incompletos), temos diantes de nós dois quadros mais ou menos atuais:

1. ${ }^{\circ}$ o da França - país densamente povoado, de índice elevado de população ativa, agrícola ou industrial, culto e amplamente escolarizado, regido em tôda a sua extensão por um direito uniforme - com um índice de advogados igual a 15,6 por cem mil habitantes;

2..$^{\circ}$ o dos Estados Unidos - país que difere da França pela menor densidade demográfica, pelo ímpeto maior no desenvolvi- 
mento e pela heterogeneidade do direito que regula a vida interna de cada unidade federada, com um indice igual a 112 advogados por cem mil habitantes.

Isto pôsto, passemos ao caso do Estado de São Paulo.

As carreiras jurídicas no Estado de São Paulo.

Segundo a legislação vigente, qualquer cidadão brasileiro formado em faculdade de direito do país (ou mesmo em faculdade estrangeira, desde que revalide o seu diploma) pode candidatar-se em São Paulo a todos os cargos ou carreiras para cujo exercício se requer aquela formação. Isto porque os diplomas de escola superior, em nosso país, têm validade nacional. Em certos casos exige-se concurso de provas: para juiz de direito ou promotor público; para advogado do Estado ou delegado de polícia. Todavia, do bacharel que pretenda apenas advogar, nada é exigido a não ser a inscrição no quadro da respectiva Ordem, secção de São Paulo.

Em 1960 assim se distribuíam no Estado os titulares de cargos cujo provimento inicial se faz por concurso de provas: Magistrados, 364; membros do Ministério Público, 282; Advogados do Estado, 400; Delegados de Polícia, 594. Total: 1940. Não incluímos na relação vinte cargos de Juízes de Direito, quarenta de Advogados do Estado e sessenta e seis de Delegados de Polícia, criados recentemente mas ainda não providos.

Quanto aos advogados inscritos na qualidade de profissionais liberais, seu número não tem limites e vem crescendo de ano em ano. Eram 7.583 em 1957; passaram a 9.840 em 1960 - o que indica um acréscimo de 2.257 em três anos. Sabendo-se que o censo de 1960 atribuiu ao nosso Estado a população de 12.874.088 habitantes, (dos quais 3.792.496 na Capital), chega-se para São Paulo, naquele ano, ao índice de 76,4 advogados por cem mil 
habitantes. Temos, pois, proporcionalmente, quase cinco vêzes mais advogados que a França e mais de $56 \%$ do índice norte-americano.

Os 9.840 advogados inscritos para o Estado distribuíam-se em proporções muito desiguais entre a Capital e o Interior: havia na Capital 7.393 advogados, ou $75,17 \%$ do total, embora o respectivo Município, segundo o recenseamento de 1960 , tenha sòmente $29,45 \%$ da população total do Estado. Para o Interior, que possui os restantes $70,55 \%$ da população, sobraram 2.447 advogados, isto é, $\mathbf{2 4 , 4 5 \%}$ dos inscritos na secção paulista da Ordem. Repetindo êsses dados e pormenorizando um pouco a situação do Interior, eis a seguir a distribuição proporcional dos advogados pelas 174 Comarcas do Estado (entre estas não incluímos as que não foram ainda instaladas):

\section{fndice de advogados por cem mil habitantes}

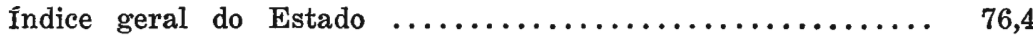

Comarca da Capital ......................... 195,0

5 Comarcas de mais de 50 advogados $\ldots \ldots \ldots \ldots \ldots \ldots \ldots \ldots$ 166,0

$22 \quad$ - de 50 a 21 advogados $\ldots \ldots \ldots \ldots \ldots \ldots \ldots \ldots . \ldots \ldots 41,1$

$21-$ de 20 a 11 advogados $\ldots \ldots \ldots \ldots \ldots \ldots \ldots \ldots . \ldots \ldots$

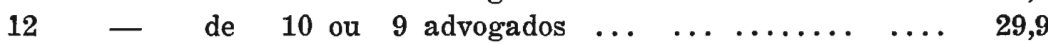

$14-$ de 8 ou 7 advogados $\ldots \ldots \ldots \ldots \ldots \ldots \ldots \ldots .31,0$

$17 \quad \ldots$ de 6 ou 5 advogados $\ldots \ldots \ldots \ldots \ldots \ldots, 16,7$

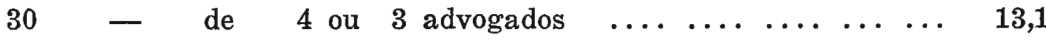

$38-$ de 2 ou 1 advogados $\ldots \ldots \ldots \ldots \ldots \ldots \ldots \ldots .9 ., 1$

$14-$ de nenhum advogado $\ldots \ldots \ldots \ldots \ldots \ldots \ldots \ldots \ldots, 0 \ldots$

Observe-se que, à medida que se eleva o total de advogados das sucessivas Comarcas, eleva-se também (salvo ligeira discrepância) o índice dêsses profissionais por cem mil habitantes. Isto significa, como é obvio, que, guardadas as proporções, aquêle total aumenta mais ràpidamente que o número de habitantes. Fenômeno análogo já foi, aliás, observado por nós em referência aos médicos (V. Boletim n. ${ }^{\circ}$ 1). Não é, portanto, só o volume da população que influi sôbre o mencionado aumento: também a intensificação das relações sociais, a complexidade 
crescente dos negócios, e o maior vulto dêsses mesmos negócios (sem falarmos no poder atrativo dos centros populosos) exercem, no caso, um papel complementar.

Certas situações especiais devem estar concorrendo no sentido de anular ou enfraquecer o poder de atração de uma ou outra Comarca. Eldorado, por exemplo, o velho centro de mineração que foi Xiririca, o qual, segundo prognóstico de 1879, conteria em si "elementos de riqueza e progresso" para um "futuro brilhante" (Azevedo Marques) - é Comarca desde 1875, mas não residia alí, em 1960, nenhum advogado. São Bento do Sapucaí, Freguezia desde 1832, Vila desde 1858, Comarca desde 1890, estava em 1960 sem advogado residente. Cachoeira Paulista, Cananéia, Patrocínio Paulista, Piedade e Piracáia — todos sede de Comarca a partir de 1892 - não tinham advogado em 1960. Em idênticas condições se achava Palmital (Comarca desde 1944), além de Franco da Rocha, General Salgado, Matão, Monte Azul Paulista, Presidente Bernardes e Regente Feijó, que são Comarcas de 1953. Delas havia quatro, entretanto, que contavam, para cada uma, com os serviços de um advogado provisionado, a saber: Palmital, Patrocínio Paulista, Piedade e São Bento do Sapucaí. ${ }^{1}$

\section{A pletora de advogados no Estado de São Paulo.}

Tem-se dito reiteradamente que há em São Paulo pletora de advogados. Alegar o fenômeno é fácil; mas prová-lo objetivamente, não é. Houve tentativas nesse sentido em vários países, segundo Calamandrei, que as resume. Na verdade o êxito não foi grande, pois os resultados de tais estudos se exprimiram através de média

1. Dos Senhores Juízes de Direito de Comarcas recenseadas como "sem advogado" aos quais oficiamos solicitando pormenores, e alguns dos quais já responderam, seus informes serão posteriormente incluídos no texto do Boletim. 
entre valôres destituídos de homogeneidade. Tanto que o mestre italiano, depois de referí-los, se limitou a formular êste comentário: "Nas condições atuais da profissão, a "causa forense" representa para o advogado, não mais a matéria prima normal do trabalho profissional, e sim a raridade, a guloseima esquisita, o prêmio da loteria". Isto para a Europa Ocidental. Quanto aos Estados Unidos, as indagações alí efetuadas por HARold LASKI (o mentor intelectual do laborismo inglês) levaram-no a concluir pela dúvida: não se sabe se há, ou não, excesso de advogados na Federação Norte-Americana.

E no Estado de São Paulo? Aquí, vários indícios apontam no sentido da pletora, formando assim uma prova cumulativa.

Para começar, confronte-se a nossa situação com a de país de análogo tipo de cultura e de análoga formação jurídica, como é a França. O "Bureau" francês de Estatística Universitária (citado acima) adverte que o índice de advogados, naquele país, se estabilizou há muitos anos em tôrno de 16 profissionais por cem mil habitantes, ao passo que entre nós êsse índice alcança, presentemente, a proporção de 76,4 por cem mil, isto é, quase o quíntuplo da proporção francesa. Será porque a França é um país já estabilizado, e São Paulo se acha por ora em fase de desenvolvimento? Duvidamos que entre duas comunidades - uma em desenvolvimento, outra já desenvolvida seja aquela que precise de maior número de juristas.

Outro elemento probatório de valor, é o testemunho dos advogados experientes. Ao acaso dos encontros ocasionais, interrogamos algumas dezenas, entre os da Capital e os do Interior do Estado. Foram unânimes em afirmar a pletora, embora vacilantes quanto à prova. Um dêles - jurista até à raiz dos cabelos - achou fútil a pesquisa, pois "os fatos notórios" (disse, citando a lei)" independem de prova". Diversos exprimiram sua convicção mediante porcentagens, como é de uso entre os que pretendem fortalecer as respectivas avaliações: "- Só 30\%, só $20 \%$ trabalham!" Em Comarca do Interior, o profissional apon- 
tado como o de maior clientela respondeu: "Aqui somos doze mas só três de fato têm serviço; só êsses três vivem da advocacia". Outro, da Capital, mas conhecedor de certa Comarca do Interior, asseverou: - "Há ali cinco advogados que quase nada fazem e um que faz quase tudo". Dos advogados recentes é raro ouvir declarações de otimismo comparáveis às de um dêles, formado há dois anos. Êste, que instalou escritório na Capital desde a quarta série jurídica, já se julga vencedor. "- Sempre me sentí vocacionado!" - informou. E repetiu várias vêzes o neologismo, que tem para êle, ao que parece, magia de palavra de estímulo. São maioria, entretanto, os que verificam logo aos primeiros meses que não estavam "vocacionados" - e desistem.

As tentativas de fazer carreira por parte dos "não vocacionados", ou o desânimo de muitos, antes mesmo de qualquer tentativa, levam grande número de jovens bacharéis a fechar para sempre os livros de direito e a cuidar de outra coisa. É interminável a lista dêstes deslocados, como escreveu em 1952 o relator dêste Boletim. Donde haver por aí (dissemos então) bacharéis lavradores, bacharéis pecuaristas, bacharéis negociantes, bacharéis gerindo fábricas, bacharéis professôres de ginásio, bacharéis banqueiros ou bancários, bacharéis corretores de praça, bacharéis escriturários de repartição, bacharéis postalistas, bacharéis no Exércíto ou na Fôrça Pública, bacharéis na Aviação, bacharéis nas agências de publicidade, bacharéis no teatro, no rádio, no futebol... De então para cá, graças aos informes colhidos em comemorações de formatura, novas posições ocupadas por bacharéis em direito pudemos recensear: a de televisionista, a de inspetor de ensino, a de gerente de restaurante, a de balconista de botequim, a de oficial de justiça, a de palhaço de circo (dois pelo menos; aliás excelentes!), a de caixeiro viajante, a de bibliotecário... Tôdas as profissões são dignas, desde que exercidas com honestidade: mas é anti-econômico, e por vêzes é também cruel preparar um jovem durante cinco anos para a advocacia ou a magistratura e, ao fim 
do curso, dizer-lhe: - Não há serviço para você! Enrole - seu diploma e vá cuidar de outra coisa.

Dois indícios ainda, referidos por Calamandrei, não são desconhecidos em nosso meio: o apêlo à assistência financeira e as infrações da ética profissional. Os que aludem a êste último indício (mencionado, aliás, não sòmente por advogados, mas também por juízes e promores) pintam com tintas sombrias o quadro respectivo; mas entendem que nesse setor a apuração dos fatos é difícil.

\section{De onde vêm os advogados inscritos em São Paulo.}

Com a ajuda prestimosa e eficiente da Secretaria da Ordem (secção de São Paulo), teria sido possível averiguar, caso por caso, qual o Estado de nossa Federação ou, eventualmente, qual o país estrangeiro de que proveio cada um dos advogados das Comarcas paulistas. Contudo, o interêsse dessa laboriosa investigação pareceu-nos diminuto e fora de proporção com o esfôrço que teríamos de solicitar. Limitâmo-nos, por isso, a registrar em seguida, a título de amostra, tão sòmente a proveniência dos advogados que, inscritos em 1960, se formaram fora de nosso Estado.

$$
\text { Inscrições de } 1960 \text { - Advogados formados fora }
$$

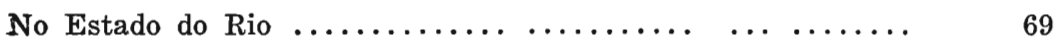

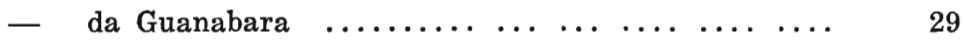

- de Minas Gerais ............................ 18

- do Paraná $\ldots \ldots \ldots \ldots \ldots \ldots \ldots \ldots \ldots \ldots \ldots$

- de Alagoas $\ldots \ldots \ldots \ldots \ldots \ldots \ldots \ldots \ldots \ldots \ldots \ldots, 4$

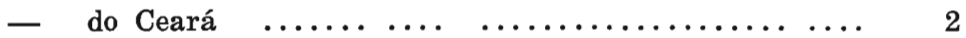

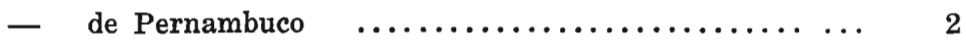

- do Maranhão, Bahia, Espírito Santo, Goiaz e Rio Grande do Sul (um em cada) ............. 5

Em Madrid (Revalid. P. U. c. de S. P.) ............... 1 
Do total acima, a primasia cabe à Faculdade de Direito de Niterói, que por sí só forneceu 68 (ou quase $50 \%$ ) dos 137 advogados a que se refere o quadro acima. Vem a seguir a Faculdade do Triângulo Mineiro (Uberlância), que contribuiu com 15 inscrições.

A propósito de tais casos, parece-nos oportuno citar aqui um trecho de relatório oficial arquivado no Ministério da Educação, referente ao funcionamento da Faculdade de Direito de Niterói durante o ano letivo de 1951, e já apreciado pelo Conselho Nacional de Educação. "Os alunos desta Faculdade (escreveu o zeloso Inspetor) residem na maioria em São Paulo, de modo que é pequeníssima a freqüência às aulas". Êsses alunos de São Paulo (continua o relatório) "aqui só vêm para as provas parciais, exames e colação de grau".

Ùltimamente, entretanto, (continuamos por nossa conta), a clientela paulista das escolas jurídicas que se satisfaz com apenas tomar exames e colar grau, não precisa mais transpor as fronteiras do Estado: aqui mesmo resolverá os seus problemas.

\section{Super-produção de bacharéis.}

Em relação à respectiva população, o Estado de São Paulo está produzindo mais que o dôbro dos bacharéis que os restantes Estados brasileiros produzem; quase o dôbro dos que se formam no Brasil em conjunto; e quase o dôbro dos que se graduam nos Estados Unidos. Eis os índices apurados por nós:

\section{Número de bacharéis que se formaram}

Nos Estados Unidos

No Brasil ém conjunto

No Brasil sem S. Paulo

Só no Estado de S. Paulo
(1958) .... 9.433 ou 5,4 p. cem mil hab.

(1959) $\ldots . .3 .562$ ou $5,4 \quad-$ -

(1959) $\ldots .2 .500$ ou $4,6 \quad--$

(1959) $\ldots . .1 .062$ ou $9,6 \quad--$ 
O desgaste do quadro de advogados é pequeno em São Paulo: 271 baixas nas inscrições da Ordem, em 1957, ou $3,5 \%$ dos integrantes daquele quadro, cujo total ascendia então a 7.583. Exportação para os outros Estados, não parece que exista a não ser em proporções muito modestas, compensadas largamente (ao que supomos) pela importação, que em 1960 foi de 137 advogados.

Por quê se formam assim tantos bacharéis? Para que tanta fartura de juristas? Que motivos levam certos Municípios a criar Faculdades de Direito, ou impelem o Estado e a União a subvencionar institutos particulares dessa categoria, alguns dos quais (como dissemos pùblicamente em 1957) proporcionam vultosos lucros aos seus proprietários? $O$ assunto é de extraordinário interêsse para a comunidade paulista, que se defronta hoje com graves problemas de solução cara, entre os quais o da educação popular, e, ainda, o do encaminhamento das novas gerações em direção a atividades mais consentâneas com os nossos propósitos de desenvolvimento.

O primeiro fator etiológico dessa conduta, está na tradição - a tradição de preconceitos contra o trabalho manual vinda da antiguidade, e que a Idade Média fortaleceu ao equiparar os títulos universitários (especialmente os de direito) aos foros de nobreza. Uns restos do preconceito ainda persistem entre nós. Foi o que mostramos em 1944 ("Por quê a Faculdade de Direito?"), e o que Hutchinson verificou em 1956, através de pesquisa mais disciplinada "(Hierarquia de Prestígio das Ocupações"). A despeito de tudo quanto a realidade nos mostra, a mocidade paulista teima na corrida para os cursos jurídicos, fascinada com a miragem da ascensão social e com as perspectivas de ganho fácil. Duas outras carreiras - a Medicina e a Engenharia - vinham de longa data se emparelhando com a de jurista: mas, por um segundo fator, atuante desde o Império e agravado a partir de 1930 , aquêles dois cursos 
vêm sendo vencidos pelo de direito. Este segundo fator é a liberalidade com que se autoriza, no país, a abertura de novas escolas jurídicas; é a indulgência com que se convertem bacharéis recém-formados $\mathrm{em}^{\text {" }}$ professôres de direito"; é a sem-cerimônia com que muitas dessas "faculdades" distribuem os seus diplomas.

\section{Regime de facilidades.}

Sim: o que mais vem influindo para produzir essa perniciosa inflação de bacharéis, é o regime de "facilidades" em matéria de novas escolas de direito. Nada mais simples do que obter para elas uma instalação "satisfatória" em salas de grupo escolar desocupadas durante a noite. Quanto ao corpo docente - real para o gasto, fictício para a figuração oficial - existem critérios rigorosos para a sua escolha, mas êsses critérios não funcionam; os professôres iniciais são interinos, mas nessa situação permanecem indefinidamente; a Constituição reclama concurso para as cátedras, mas a ogeriza aos concursos vence a Constituição.

E os alunos? Para o propósito de agenciá-los e conservá-los, também vigora o regime de "facilidades" - tanto em relação aos exames como no que se refere à freqüência às aulas, convertendo-se em rotina aquilo que a lei instituiu em caráter de exceção. Os pareceres e debates do Conselho Nacional de Educação desta última década, se bem que freqüentemente omissos, são mesmo assim, quando lidos nas suas linhas e entrelinhas, férteis em informes que tornam patente a gravidade da situação criada pelo regime de "facilidades" (convém insistir nesta expressão!) - regime que vem influindo pejorativamente na qualidade da corporação de juristas de nosso Estado e na de todo o Brasil. 


\section{Sugestões finais.}

O Govêrno da República prestará, portanto, um grande serviço à Nação se decidir-se a pôr côbro à série de irregularidades que viciam presentemente o sistema nacional de ensino superior em todos os seus setôres, mas principalmente em relação ao ensino do direito.

No século passado os cursos jurídicos brasileiros, embora deficientes, exerciam papel importantíssimo como centros de convívio cultural da mocidade inteligente do país, e como instrumentos de unificação nacional. Hoje, porém, em virtude dos reclamos cada vez mais imperiosos da vida moderna, devem êles aprimorar-se no desempenho de suas tarefas específicas, isto é, na formação de profissionais do direito e na elevação da cultura jurídica. Em nossa opinião, os institutos que adotem êsse programa, que se organizem em regime compatível com êle e recrutem professôres de idoneidade indiscutível, são os únicos a merecerem autorização de funcionamento, quando a necessidade o exigir. $\mathrm{E}$, no que se refere ao Estado de São Paulo, os dados coligidos neste "Boletim" demonstram claramente que não precisaremos tão cedo de novas faculdades de direito.

São Paulo, 28 de junho de 1961. 